\title{
Midwife-moderated social media groups as a validated information source for women during pregnancy
}

\begin{abstract}
Background

Widespread use of the internet has fundamentally altered the way people access health information and communicate with health providers. Pregnant women are a group who are particularly highly motivated to seek out information online. However, where mothers actually obtain their information, who they trust to supply it, and whether or not it actually fulfils their needs is often unclear. This paper examines the experiences of women accessing advice and information on pregnancy and childbirth through a dedicated social-media platform, mediated by qualified midwives. The study formed part of a larger research project that focussed on professionally moderated online learning in maternity care, and the role of online communities. This paper reports on aspects of midwife mediated information provision in the context of these online communities.
\end{abstract}

\section{Methods}

Two secret (i.e. private / invitation only) Facebook groups were created. Both groups were moderated by 2 qualified midwives. One group had 17 mothers and the other 14 mothers. Both groups ran for 35 weeks.

\section{Data and analysis}

The data included the written and spoken words of group participants and midwife-moderators in i) face-to-face $(n=4)$ and online $(n=4)$ post-intervention focus groups; ii) one-to-one interviews with group participants and midwife moderators ( $n=24)$; iii) the complete corpus of text-based interaction across both groups; iv) a sub-set of private message sessions $(n=24)$ between individual participants and midwife-moderators. Thematic analysis was applied to the combined dataset.

\section{Findings}

Participants found engagement with midwives and other pregnant women via a social media group convenient and accessible. The groups provided a safe space for the sharing and validation of maternity relevant information. Members trusted their midwife-moderators to ensure information was reliable. For many members, the group became the primary source of pregnancy related information.

\section{Conclusion}

Midwife-mediated social media groups offer a highly effective way of providing individualised information provision and social support for pregnant woman. Access to a group can also significantly impact on perceptions of relational continuity. 


\section{Introduction}

Although child-birth and motherhood is often thought of as being grounded in a kind of innate biological instinct (O'Reilly, 2010; Lagan et al, 2010), in reality, such idealistic natural connections may now be all but gone (Hrdy, 2011). However, the notion of the 'good mother' still prevails, and is subtly (and not so subtly) perpetuated at every level of social discourse (Guendouzi, 2005; Hadfield, Rudoe \& Sanderson-Mann, 2007). Partly as a result of this, most expectant mothers will seek - and expect to be provided with - explicit information and advice about childrearing. Traditionally, this information has come from family and friends, health professionals, specialist literature and the media (Lagan et al, 2006; Song et al, 2012; Song et al, 2013).

The information needs of pregnant women, in the Western world, are well documented (Walsh \& Devane, 2012; Kirkham, 2004; Green, Coupland \& Kitzinger, 1998). In contrast to traditional paternalistic models of healthcare, whilst women are aware that maternity resources are finite, they now expect to be able to ask questions, seek advice and receive accurate and non-conflicting information during their antenatal care (Hildingsson \& Radestad, 2005). In a range of international studies, practicing midwives confirm that women want to be able to ask questions about their maternal care and pregnancy, make informed choices, and be clear about the implications of different options that they may be offered (McCarthy et al, 2017; Mok \& Leung, 2006). At a more practical level, women want to be able to ask questions when it is convenient for them and not necessarily once a crisis point is reached, or when their midwife is able to see them (McCarthy, 2017). A recent maternity review by NHS England (2016) also indicated that women expect maternity services to offer a wide range of information, and that this should be from multiple sources (Redshaw \& Henderson, 2015). It is acknowledged however, that they currently often do not receive the level or type of information they require from health professionals and often seek alternative sources (NHS England, 2016).

Widespread use of the internet has fundamentally changed the way people access health information and engage with health providers (Kiley, 2002). Information can be found on the internet by anyone willing to look for it, and pregnant women in particular appear to be highly motivated to do this (Lagan et al, 2010; Olson, 2005). Accessing health-based information online offers a degree of flexibility and autonomy that appeals to many mothers (Kennedy, 2017). At a pragmatic level, much of the mundane and non-urgent information that pregnant women need does not require a physical one-to-one meeting with a midwife or other health professional, so accessing information online reduces the need to travel to health centres or to wait for appointments. The online availability of pregnancy related information may foster wider psycho-social benefits too. It has been suggested that having immediate access to information that, in the past, would probably have been restricted or difficult to find, can help re-balance power inequalities between mothers and health professionals (Van de Belt et al, 2010).

There are problems with this new-found information nirvana of course. The sheer volume of information online - much of it of questionable provenance - can be overwhelming (Buultjens et al, 2012; Lima-Pereira et al, 2012). The difficulty of checking the credibility or motivation of providers can also be an issue and it can be extremely difficult for people to recognise when information provision on the internet is commercially driven (Gao et al, 2013). It has also been highlighted that much of the research and evidence-based information available online is not intended for a general audience. Scientific reports and research papers with technical language may be incomprehensible to many people (Sacks \& Abenhaim, 2013), and without knowledge of how to filter or interpret evidence, there is always the potential for bad decision making (Kelton, Fleischman \& Wallace, 2008). Despite these drawbacks however, it is widely acknowledged that in general, women are now in a far better position 
to find information about their pregnancy, and make choices based on evidence, rather than professional opinion or the broad vagaries of health policy (Lagan et al, 2010, NHS England, 2016).

In addition to being able to access significantly more maternity related information and research through the internet, many pregnant women also now utilise web-based applications or become part of online communities (Johnson, 2015) where they can meet other mothers, share experiences, offer each other social and emotional support and ask and answer questions (Eysenbech et al., 2004). Social media use by women is the UK is extremely high, with $93 \%$ of $16-24$ year olds, $88 \%$ of 24-34 year olds, and $85 \%$ of 35-44 year olds now classing themselves as active users (ONS, 2018). Groups specifically tailored for pregnant women have similarly proliferated over the past decade (Eysenbech et al, 2004), and added to these are any number of privately created groups hosted on general social media platforms such as Facebook or Twitter.

What has been unclear is whether or not it is possible to capitalise on existing widespread engagement with social media and develop professionally moderated groups specifically for women receiving maternity care. This could offer an opportunity for meeting women's information needs to support choice (Ormandy, 2010) or achieving informational continuity, or continuity of care via information exchange between patients and professionals (Heaton et al, 2012). In this paper we report on selected findings from a larger mixed-methods study which aimed to explore this question and examine role that such groups might play in fostering relational continuity for pregnant women. Relational continuity is defined as an ongoing therapeutic relationship between a patient and one or more providers (Haggerty et al, 2003: 1220), and as a broad concept has become a key feature of current maternity care provision. Here, we focus specifically on how the informational aspects of midwife moderated groups impact on the development of relational continuity.

\section{Methods}

\section{Setting and recruitment}

The study involved two large NHS Trusts in the north of England. Women attending maternity services for their first scan or booking appointment were approached by the attending midwife and provided with information about the study. Of 106 women approached, 72 completed an expression of interest form and were invited to join the study. 31 women eventually agreed to take part in the study and completed a consent form.

\section{Inclusion criteria}

The study was limited to pregnant, English speaking women over 16 years of age, without a serious mental health condition. These restrictions were required because moderating midwives needed to be able to communicate effectively with all participants without the need for specialist skills or knowledge. Two midwives were seconded from each Trust for the duration of the study.

\section{The Facebook groups}

Facebook was selected as a platform for the study because it has the highest reported use by women aged 19-29 years (Fox, 2016; Duggan and Smith, 2013), and is easily accessed on a wide variety of devices (Bacigalupe, 2011). A secret Facebook group was set up by the respective midwife moderators for each Trust. Facebook has three levels of privacy setting and secret is the highest. The secret privacy setting meant that the group was open and visible to invited members only, secret groups are not google indexed or searchable within or outside Facebook. This was an important feature which safeguarded the privacy and confidentiality of members from the outset. 
A researcher monitored each Facebook site and made suggestions to the moderators about potential content for posts, and strategies to engage members and generate activity. Whilst there were no breaches of confidentiality, a governance structure was established to ensure escalation of any breach to the principal researcher. Moderators were required to check postings on the group several times a day and be available to answer queries and verify information. The online group and participants took the title 'Facemums' while the midwife moderators were referred to as 'Facewives.'

Data collection and analysis

Data were collected over 35 weeks and included material from: i) Four face-to-face $(n=4)$ and four online $(n=4)$ post-intervention focus groups; ii) one-to-one interviews with group participants $(n=24)$ and midwife moderators; iii) the complete corpus of interaction posted across both Facemums sites during the; iv) a sub-set of private message sessions $(n=24)$ between individual participants and midwife-moderators.

A thematic analysis of the combined data set was undertaken which broadly followed the model outlined by Braun and Clarke (2013). This incorporated stages based around: familiarisation and transcription; initial coding; searching for and reviewing identified themes. RM analysed the data and thematic findings were checked by members of the wider project team (see acknowledgements).

\section{Findings}

31 pregnant women and 4 midwives participated in the study. Basic demographic information was collected on a voluntary basis. The average age range of the Facemums who disclosed their age was 23-41 years. All Facemums who disclosed information were working and employed in a diverse range of jobs at the time they joined the group. Fifty percent of those who disclosed information (13) were graduates and $88 \%$ had some university education. In total $50 \%$ of mothers were primigravid (first pregnancy) (13), 53\% were nulliparous (not given birth but may have been pregnant previously) (14). One mother disclosed that she had been pregnant before but had not given birth. The rest of the participants who disclosed information (13) were expecting their second or third baby. One mother (FMB3) was expecting twins, the rest were singleton pregnancies. The demographic elements of the sample are reported in more detail elsewhere (McCarthy, 2017).

Core themes to emerge related to improvements in relational continuity and informational continuity for mothers who engaged with a Facemums social media group. The findings on relational continuity are reported elsewhere (McCarthy et al, 2017). This paper presents findings related to informational continuity, and specifically, three sub-themes: i) Engaging with a special interest socialmedia group; ii) Finding information on the internet; iii) Professional and peer-based information sources.

\section{Engaging with a special interest social-media group}

All of the mothers across both groups expressed appreciation that they could connect with midwives and other mothers to obtain information electronically. This was evident across the electronic data, the focus groups and in individual interviews.

'I didn't join it to meet people at all. I did just join purely for the midwife... I personally loved the group, I liked having the security of being able to contact a midwife... it made me feel secure.' 
Difficulty in accessing a midwife for professional advice was a repeated source of frustration for mothers. This was in contrast to the convenience that engaging with a professionally moderated group offered. Participants reported that they could access the midwives assigned to their group more easily, and get a quicker response than they could using traditional NHS routes:

'I did ask my midwife... and she said go to your GP and I thought I can't get an appointment...so then I posted on the site.'

'Every time I went to my doctor I would be waiting at least an hour before I went in, when you're still working and you only get an hour and then it comes out of my wage.'

FMB12

'Obviously if you go to the GP or the midwife you have to wait you have to make an appointment but the Facewives are just there...its really great'.

FMC14

'It's just a lot easier and approachable I would say where it's not easy to approach your GP.'

Although mothers felt that certain types of information need could be addressed by their Facemums group, they still wanted to be seen by a midwife for physical check-ups and one-to-one contact. There was a consensus however, that some face-to-face appointment time could usefully be replaced by online access to a midwife:

'It was more of an inconvenience to go to these appointments, because it was like especially because at the end it was like every two or three weeks and I knew pretty much I was okay, I was still working at the time and it was like if I could have just gone to Boots and do it in the evening at the weekend I definitely would have done that..'

FMC4

'...so often I felt like I was doubling up on appointments unnecessarily. And also, half the time I was in out so quickly I just thought yeah I didn't need this appointment and particularly because I work and I've got another little girl ... it was just more convenient for me to manage things in the evening and online...I certainly don't think it would be unsafe, I think it would alleviate some of the pressure on appointments, but I don't think it wouldn't mean that you wouldn't get as good a care.'

FMB7

'I'd give them all up; in my experience I'd give the face-to-face up to have this. I don't think I got anything out of the face-to-face other than having the actual check-up.'

FMC12

'Because when you're in an appointment atmosphere...l go in every...when...l would ring my husband and go, 'Right, I'm just phoning for my appointment now', and he'd say, 'Right, have you got the things you need to ask', and I'd be like, 'Yeah, I know what I'm asking', and I would come back and go, 'I didn't ask this, I didn't ask any of them'. Because you don't, in an appointment atmosphere, you don't, and I'm always-I don't want to take up their time- because my midwife was 
always half an hour late for everything, and I didn't ever want to - I knew she was already behind, so yeah absolutely I would.' [Lose face-to-face appointments for online access]

\section{Finding information on the internet}

Rather than acting as an accessible resource for information provision, participants reported that the internet - particularly when it was approached as a kind of vast searchable repository - was often the source of worry. There was general awareness of the limitations of internet-based information. And whilst it was evidently accessible, it was viewed at best with suspicion and was frequently cited as problematic in its own right:

'You can get a bit confused on the internet.'

That's exactly what I am like! My point exactly and I found that I couldn't understand my poly (totally separate thing I know) as the Internet can be so misleading and I wanted to know why I had it and still very little info...I just had to accept it was one of those pregnancy "things" but being first time mum/first pregnancy it was hard! I was also diagnosed with it at 36 weeks!

FBAD2 (post)

[On searching for information on the internet] 'It's not good, and it's not good for people who are pregnant and who have brand new babies if, you know, they've got no experience.'

FMC11

There was general consensus that even with sites that were considered reliable, such as NHS Choices, participants found their information needs were still often not met, and that not all (and in fact, very little) information on the internet was actually helpful or could be trusted. The overwhelming availability of unfiltered information on the web made participants feel anxious, but the Facemums site provided a forum to check the accuracy of information and to consolidate understanding:

'I am more than capable of going on the NHS website if I have a question, so I guess I' $m$ kind of looking for something different...it's really important for somebody to say is that advice right or have you understood it, it's really important.'

The sense of information overload on the internet, and worries about the provenance of sources led to a heightened need to check the accuracy and relevance of information. This even extended to information provided by another health professionals:

'... [the midwife moderators] were an independent opinion. I think if you're having a sail through pregnancy maybe you don't want that second opinion, you're trusting what you're 
being told, not that my midwife ever told me anything wrong, but it was nice to just come away and sound them out [the midwife moderators] about something you'd been told.'

FMC5

Going to see my midwife Thursday for my 38 week check although I'll be $38+6 ;$ spoke to antenatal today who informed me my platelets are stable so although I was considered high risk and for consultant led care they don't want to see me now until I go into labour? Not sure if that's a good thing or not, I don't have a birth plan now as they wanted to do that when they saw me? Just hoping little one makes an early appearance $v \mathrm{~T}_{\mathrm{j}} 8 \mathrm{8}$

FBAD3 (post)

'...they (the midwife moderators) are so good at following it up and ... later saying how did you go on? What happened? Any questions, or whatever, that to me is just fantastic.'

FMC1

General internet searches for information on pregnancy and motherhood were not entirely replaced by involvement in a Facemums group. However, when participants used Google to find information, they often verified their findings with the group. Participants recognised that conducting indiscriminate internet searches for pregnancy related information was not necessarily helpful:

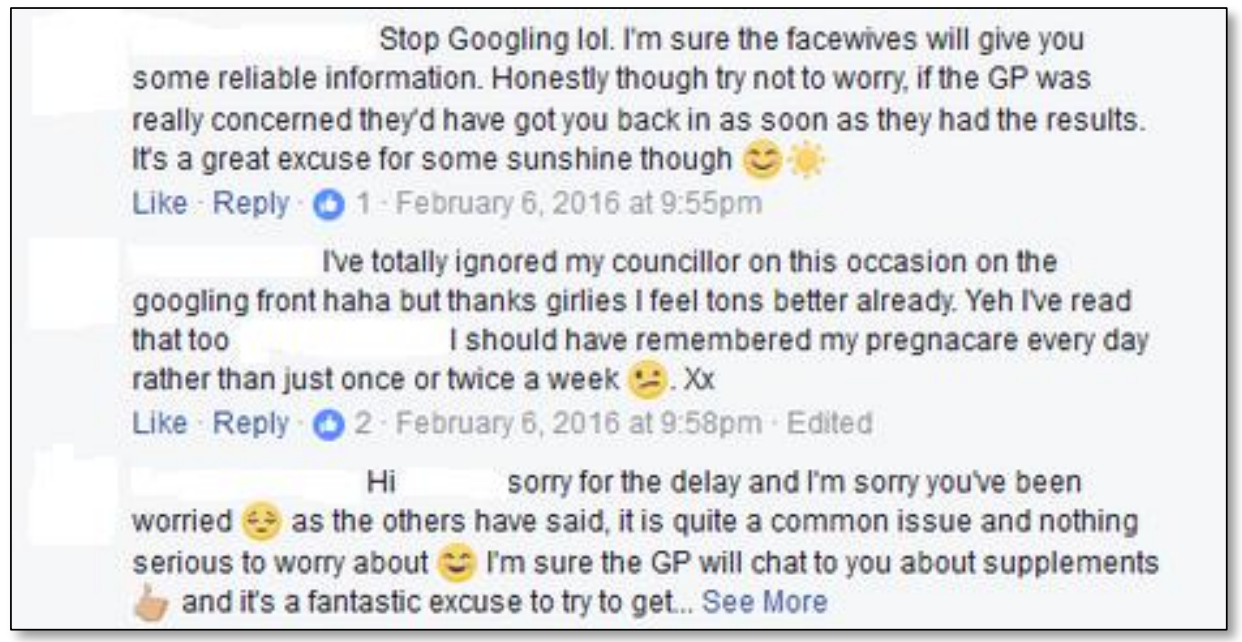

FBAD 9 (post)

'Before I joined the group I used to go to Google and I used to ask questions but when I joined the group I thought that this communication was better... I could learn more from it, so at that point I stopped going to Google because I could listen to the Facewives.' 
'For some of the pure health advice and the midwives are there for that, because I know that they know it, because of that, now I just don't use a lot of other resources.'

\section{Professional and peer-based information sources}

Participants wanted access to a midwife for professional, accurate and evidence-based information and advice, and the groups provided this.

'They're looking stuff up for you, they are doing the research for you, giving you stuff to go away and read so it's not just about them giving you stuff and you having to take their word for it they giving you the evidence as well and I guess for me being a clinical psychologist I want the science behind, you want the evidence.'

'It's enough to know they are in the background. So you know that if it was something to be concerned about, they'd comment.'

Participants also appreciated that because the midwife-moderators were not involved in the actual delivery of care to any of the mothers in their particular group, they were freer to offer contributions and advice based on both their professional and personal experience:

'I don't think if [the midwife-moderators] had been doing a kind of 'the NHS party line is', that wouldn't have worked. The fact that it's them being themselves that's really important to me... when they're talking to you it's them talking to you, it's not the NHS talking to you... I really valued that, I liked the fact they were prepared to say the guidance says $X$ but ...'

FMC1

'What I like is it's not preaching about things, they're not saying you should do this and you should do that, what it is, is advice and guidance and that's what I think is brilliant about it.'

FMC3

'I felt you could ask anything, there was nothing you couldn't ask, nothing like a what sort of nonsense question is this, every question asked matters to them and they go to lengths to answer them.'

Participants recognised that not all queries needed to be answered immediately. However, they reported feeling safer knowing they could ask a question at any time if they wanted to. The speed of response for information or advice did not appear to impact on how highly participants valued the group. The effect of simply being able to post a question on the group page was reassuring, irrespective of how long it was before a response appeared. 
'...and it's just as important having somewhere to put it doesn't matter whether there's an answer or not.'

'As long as you know that it's going to be read and if you need an answer, you'll get it...provided it's not a week later.'

FMC11

'...this time it's different (second pregnancy) if I have thought of something it's been really nice just to go on the Facemums than just think oh well ... just check that on the site.'

Although the primary reason for most mothers joining the Facemums initiative was to more easily access professionally validated midwifery advice, as the groups became established the information and guidance originating from, and shared between participants themselves became increasingly significant:

'Sometimes it's good to just speak to a mum.'

'Because they are midwives, they've got to give you the evidence and that's great, I want to know that, I want to know what the evidence is. However, I also want to know what Mums who have been in that situation [say] ... and that's when you'll make the best decision.'

'And obviously sometimes the Facemums would answer before the Facewives and they'd know the answer...you value their response just as much.'

Participants recognised that the midwife-moderators were not 'experts' in motherhood and had a clearly defined area of expertise. Whilst they were perceived as being the experts during pregnancy, this was less evident once mothers had given birth. By this time, group dynamics were stabilised and well-established. The women were well known to each other and valued each other's opinions.

'I think there's so much resources out there for first time mums but the different advice that you get it's just... it can make it even more difficult than not knowing at all sometimes I think. So it's good to just speak to a mum.'

'No offence to them, but like they don't know, like the mums don't really know the answer (in pregnancy), so if they want to give me advice that's fine but I would still like wait for the Facewives ... but now that I am not pregnant they [the midwife-moderators] haven't got the answers for me.' 


\section{Discussion}

In line with other studies focusing on the online activities of pregnant women (Sinclair et al, 2018; Kim et al, 2010), the women who joined this study were all very familiar with using the internet and engaged with it as an intrinsic part of their every-day lives. They did not start using it to find information just because they became pregnant. Similarly, the idea of joining a special-interest socialmedia group was nothing new to them. What made the Facemums initiative appealing to the mothers who took part was that it took elements of online engagement that were familiar and useful to them, such as easy access to a vast amount of information and the ability to connect and interact instantly with other people, and mitigated some of its key drawbacks. In particular, it offered the kind of individualised and reliable responses to their concerns that they often needed (Walsh, 2018). It allowed them to verify the trustworthiness and credibility of information and helped reduce information overload and confusion (Lewallen \& Côté-Arsenault, 2014; Jay et al, 2018). From a theoretical standpoint regarding information needs in health care, Facemums provided knowledge to satisfy particular goals in the context women found themselves in at a particular time (Ormandy, 2010).

In line with broader studies of internet use for accessing healthcare information (Swar et al, 2017; Klerings et al, 2015), and more specific international studies dealing with maternity care (Sayakahot \& Carolan-Olah, 2016; Narasimhulu et al, 2016) there was awareness of the limitations of conventionally accessed information from the internet. The huge amount of - often conflicting - material available was often a source of worry, and much of it was viewed with suspicion. Engagement with the group crystallised these perceptions. Although general internet searches for information on pregnancy and motherhood were not entirely replaced by information sourced through Facemums, when participants used Google to find information, they often asked the group to verify their findings. Implicit in this validation was the knowledge that a midwife-moderator would be tracking the interaction and, even if they were not directly contributing to a particular thread, would step in to clarify any misinformation.

Participants reported that in contrast to their experiences with traditional NHS services (Butler et al, 2015), they were able to access to the midwives assigned to their group, and obtain a quick response. Along with general postings to the group as a whole, mothers could send private messages to other people on the forum without content being seen by the wider group. Significantly, participants tended not to use the private message function available on Facebook to contact their midwife-moderators in the first instance. Queries were usually sent openly to the group first, even if they were clearly intended for the midwife. This is interesting because it reflects how participants recognised that not all queries needed to be answered immediately. It was simply the knowledge that they could ask questions at any time, and would receive a response that made them feel secure. The actual speed of the response - from either other members of the group or the midwife-moderator did not appear to impact significantly on how highly they valued the group.

A significant interactional issue to note here is that at the start of the study the midwifemoderators were only given broad guidance on how they should approach the management of a Facemums group. Apart from basic ground-rules about maintaining confidentiality and regularly checking the site, they were given free rein to develop and run things however they wished. This had the unexpected but, in the event, highly informative outcome that the two groups in the study evolved contrasting working styles. In one group, the midwife-moderators tended to be very active on the forum and developed close informal ties with the mothers. In effect the group took on the 
characteristics of a functioning community of practice (COP) (Wenger-Trainer et al, 1998), where the mothers eventually relied less and less on the moderators for information validation, worked together to answer questions collegially and began to look to one another for advice and support. Interactions within the other group maintained a more formal hierarchy with the midwife-moderators remaining the focus of cognitive authority (Reith, 2002) throughout the study. This tended to limit the degree to which truly collaborative interrelations developed even though a high degree of social cohesion was still evident between members.

Interestingly, these contrasting approaches appear to have had little impact on the success of both groups in delivering the information and support needs of their mothers. As we have outlined elsewhere (McCarthy et al, 2017) it seems that the availability of a group per se - regardless of whether or not it develops into an entity with the characteristics of a fully-fledged CoP - has far more impact on a mother's experience of relational continuity than the way the group is actually run.

Participants trusted the input of their midwife-moderators, and the process of being able to access reliable and verifiable information through their Facemums group changed their information seeking behaviour. Before joining the study, participants reported using well established internet sites such as Netmums (https://www.netmums.com) and Mums.net (https://www.mumsnet.com) to access information about pregnancy, birth and motherhood. Social network sites such as these were not highly rated however, and in line with work by McLure et al (2000), had the unavoidable drawbacks of any large online community: interactions tend to become depersonalised, it can be difficult to ascertain the provenance of information, and there may be issues of trust as the large number of members don't know each other. In the case of Facemums, groups were sufficiently large to maintain workable interactions, but small enough to allow members to get to know one another, and for the midwife-moderators to give individualised attention when required.

This study showed that a social media-based approach can make a significant contribution to maternal information provision in line with the informational continuity approach described in other areas of care (Heaton et al, 2012). Furthermore our findings are also intrinsically linked to wider debates over the development of relational continuity in midwifery services. Difficulty in accessing a midwife - not only as a source of accurate information, but also in order to maintain a consistent and dependable relationship with her - was a key source of frustration for mothers taking part in the study. This has been acknowledged in other work seeking to improve current models of maternity care (NHS England, 2016; Sandall et al, 2016; Phillimore, 2015). Many of the barriers seen to be preventing enhanced relational continuity relate to the physical and financial expense of offering more individualised and bespoke services. The assumption has been that such services would basically require significant numbers of new (expensive) midwives (NHS England, 2016). What this study has confirmed is that incidental to providing reliable information and support, by capitalising on the freely available social media services that many mothers already engage with, informational and relational continuity can be enhanced. The two Facemums sites in our study definitely met participants' information and support needs, but they did more than that; they gave mothers a new source of continuity to underpin their experience of maternity.

\section{Conclusions}

This study was relatively small and the participants and midwife-moderators were self-selected. This may limit the generalisability that can be claimed for our findings. However, given the widespread use of this everyday digital technology and the issues faced by maternity services across the Western world, the study does indicate that professionally moderated social media groups have the potential to greatly improve information provision for women accessing maternity care. 
Membership of a Facemums group offered a safe space for pregnant women to share and access information, but more work is needed to establish whether or not the informational elements we explore here, and other key issues such as enhanced relational continuity, are repeatable at scale. To this end, a full-scale follow-up study using the model described here is currently underway in fifteen UK Healthcare Trusts, located across three regional Sustainability and Transformation Partnerships. The new study, ${ }^{1}$ which aims to recruit over 2000 pregnant women to 100 separate midwife-mediated Facemums groups, is due to report in mid-2020.

\section{Ethical approval}

The study was approved by the National Health Service (NHS) Research Ethics Committee and the University of Salford Health Research Ethics Panel. Ethics reference numbers: IRAS - 15/WS/0028. Project ID - 163663.

\section{Funding sources}

Health Education England.

\section{Clinical trial registry and registration number}

Not applicable.

\section{Acknowledgements}

The study was funded by Heath Education England. Thank you to Cristina Vasilica for advice and guidance on social media engagement techniques and optimising online relationships.

\footnotetext{
${ }^{1}$ Study name removed for review.
}

\section{References}

Bacigalupe, G., 2011. Is there a role for social technologies in collaborative healthcare? Families, Systems, Health 29, 1-4.

Bailey, L., 1999. Refracted selves? A study of changes in self-identity in the transition to motherhood. Sociology, 33(2), pp.335-352.

Butler, M.M., Sheehy, L., Kington, M.M., Walsh, M.C., Brosnan, M.C., Murphy, M., Naughton, C., Drennan, J. and Barry, T., 2015. Evaluating midwife-led antenatal care: Choice, experience, effectiveness, and preparation for pregnancy. Midwifery, 31(4), pp.418-425. 
Bjelke, M., Martinsson, A.K., Lendahls, L. and Oscarsson, M., 2016. Using the Internet as a source of information during pregnancy-A descriptive cross-sectional study in Sweden. Midwifery, 40, pp.187-191.

Buultjens, M., Robinson, P., and Milgrom, J. (2012). Online resources for new mothers:

opportunities and challenges for perinatal health professionals. J Perinat Educ, 21(2), 99-111.

Cooper, A., Gray, J., Willson, A., Lines, C., McCannon, J. and McHardy, K., 2015. Exploring the role of communications in quality improvement: A case study of the 1000 Lives Campaign in NHS Wales. Journal of communication in healthcare, 8(1), pp.76-84.

Coleman, C.K., Fanning, K. and Williams, K.N., 2015. Comparing person-centered communication education in long-term care using onsite and online formats. Journal of gerontological nursing, 41(11), pp.22-28.

Duggan, M. and Smith, A., 2014. Pew Research Center. Social media update 2013. Retrieved November, 27, p.2014.

Earle, S., 2000. Pregnancy and the maintenance of self-identity: implications for antenatal care in the community. Health \& Social Care in the Community, 8(4), pp.235-241.

Eysenbach, G., Powell, J., Englesakis, M., Rizo, C., and Stern, A. (2004). Health related virtual communities and electronic support groups: systematic review of the effects of online peer to peer interactions. BMJ, 328 (5), 1-6.

Fox, S., 2016. The Social Life of Health Information, 2011. Pew Internet \& American Life Project. Washington, DC: Pew Research Center.

Gao, L. L., Larsson, M., and Luo, S. Y. (2013). Internet use by Chinese women seeking pregnancy-related information. Midwifery, 29(7), 730-735.

Green, J. M., Coupland, V.A., and Kitzinger, J.V. (1998). Great Expectations: A prospective study of women's expectations and experiences of childbirth. Cheshire: Books for Midwives.

Hadfield, L., Rudoe, N., and Sanderson-Mann, J. (2007). Motherhood, choice and the British media: a time to reflect. Gender and Education, 19(2), 255-263.

Hansen, M. (2008). Versatile, immersive, creative and dynamic virtual 3-D healthcare learning environments: a review of the literature. Journal of Medical Internet Research, 10(3), 26.

Heaton J., Corden, A., and Parker, G. (2012)'Continuity of care': a critical interpretive synthesis of how the concept was elaborated by a national research programme. International Journal of Integrated Care, 12(2), None. DOI: http://doi.org/10.5334/ijic.794

Haggerty J., Reid R J., Freeman G K., Starfield B H., Adair C E., McKendry R (2003) Continuity of care: a multidisciplinary review. BMJ, 32722.

Hildingsson, I., and Rådestad, I. (2005). Swedish women's satisfaction with medical and emotional aspects of antenatal care. Journal of Advanced Nursing, 52(3), 239-249.

Hrdy, S.B., 2011. Mothers and others. Harvard University Press. Guendouzi. 
Haase, K. R., and Loiselle, C. G. (2012). Oncology team members' perceptions of a virtual navigation tool for cancer patients. Int J Med Inform, 81(6), 395-403.

Jay, A., Thomas, H. and Brooks, F., 2018. Induction of labour: How do women get information and make decisions? Findings of a qualitative study. British Journal of Midwifery, 26(1), pp.22-29.

Johnson, S.A., 2015. 'Intimate mothering publics': comparing face-to-face support groups and Internet use for women seeking information and advice in the transition to first-time motherhood. Culture, health $\&$ sexuality, 17(2), pp.237-251.

Kelton, K., Fleischmann, K. R., and Wallace, W. A. (2008). Trust in Digital Information. Journal of the American Society for Information Science and Technology, 59(3), 363-374.

Kennedy, R.A.K., Mullaney, L., Reynolds, C.M.E., Cawley, S., McCartney, D.M.A. and Turner, M.J., 2017. Preferences of women for web-based nutritional information in pregnancy. Public health, 143, pp.71-77.

Kaplan, A. M., and Haenlein, M. (2010). Users of the world, unite! The challenges and opportunities of Social Media. Business Horizons (53), 59-68.

Klerings, I., Weinhandl, A.S. and Thaler, K.J., 2015. Information overload in healthcare: too much of a good thing?. Zeitschrift für Evidenz, Fortbildung und Qualität im Gesundheitswesen, 109(4-5), pp.285-290.

Kim, H.K., Niederdeppe, J., Graham, M., Olson, C. and Gay, G., 2015. Effects of online self-regulation activities on physical activity among pregnant and early postpartum women. Journal of health communication, 20(10), pp.1115-1124.

Kiley, R. (2002). Does the internet harm health? Some evidence exists that the internet does harm health. BMJ: British Medical Journal, 324(7331), 238.

Kirkham, M. (2004). Informed Choice in Maternity Care. London: Palgrave Macmillan.

Kirkham, M., Morgan, R.K., and Davies, C. (2006). Why Do Midwives Stay?

Women's Informed Childbearing and Health Research Group. Sheffield: University of Sheffield.

Lagan, B. M., Sinclair, M., and Kernohan, G. W. (2010). Internet Use in Pregnancy Informs

Women's Decision Making: A Web-Based Survey. Birth: Issues in Perinatal Care, 37(2),106-115.

Lagan, B.M, Sinclair, M., and Kernohan W.G. (2006). Pregnant women's use of the internet:a review of published and unpublished evidence. Evidence Based Midwifery 4(1): 17-23

Lenzen, S.A., Stommel, W., Daniëls, R., van Bokhoven, M.A., van der Weijden, T. and Beurskens, A., 2018. Ascribing patients a passive role: Conversation analysis of practice nurses' and patients' goal setting and action planning talk. Research in Nursing \& Health, 41(4), pp.389-397.

Lewallen, L.P. and Côté-Arsenault, D.Y., 2014. Implications for nurses and researchers of Internet use by childbearing women. Nursing for women's health, 18(5), pp.392-400.

Lima-Pereira, P., Bermudez-Tamayo, C., and Jasienska, G. (2012). Use of the Internet as a source of health information amongst participants of antenatal classes. Journal 
ClinicalNursing, 21(3-4), 322-330.

McCarthy, R., Choucri, L., Ormandy, P. and Brettle, A., 2017. Midwifery continuity: The use of social media. Midwifery, 52, pp.34-41.

McLure-Wasko, M., and Faraj, S. (2000). "It is what one does": why people participate and help others in electronic communities of practice. The Journal of Strategic Information Systems, 9(2), 155-173.

Mok, E. and Leung, S.F., 2006. Nurses as providers of support for mothers of premature infants. Journal of clinical nursing, 15(6), pp.726-734.

NHS England (2016) National maternity review. better births; improving outcomes of maternity services in England. London. NHS England.

Office of National Statistics (2018) https://www.ons.gov.uk/ (accessed 29/11/2018)

O'Reilly, A. (2010). Twenty-first Century Motherhood: Experience, Identity, Policy, Agency: Colombia University Press.

Ormandy, P. (2010) Defining information need in health - assimilating complex theories derived from information science, Health Expectations, 14, pp92-104.

Olson, C. M. (2005). Tracking of food choices across transition to motherhood. Journal of Nutrition Education and behaviour, 37(3), 129-136.

Phillimore, J., 2015. Delivering maternity services in an era of superdiversity: the challenges of novelty and newness. Ethnic and Racial Studies, 38(4), pp.568-582.

Redshaw, M., and Henderson, J. (2015). Safely Delivered. A National Survey of Womens Experience of Maternity Care. Oxford: The National Perinatal Epidemiology Unit (NPEU).

Rieh, S.Y., 2002. Judgment of information quality and cognitive authority in the Web. Journal of the American society for information science and technology, 53(2), pp.145-161.

Sacks, S., and Abenhaim, H. A. (2013). How evidence-based is the information on the internet about nausea and vomiting of pregnancy? Journal of Obstetrics and Gynaecology Canada, 35(8), 697-703.

Shea, R., Bryant, L. and Wendt, S., 2016. 'Nappy bags instead of handbags': Young motherhood and self-identity. Journal of Sociology, 52(4), pp.840-855.

Song, F. W., West, J. E., Lundy, L., \& Smith Dahmen, N. (2012). Women, pregnancy, and health information online: the making of informed patients and ideal mothers. Gender \& Society, 26(5), 773-798.

Song, H., Cramer, E. M., McRoy, S., and May, A. (2013). Information Needs, Seeking Behaviors, and Support Among Low-Income Expectant Women. Women \& Health, 53(8), 824-842. 
Sayakhot, P. and Carolan-Olah, M., 2016. Internet use by pregnant women seeking pregnancy-related information: a systematic review. BMC pregnancy and childbirth, 16(1), p.65.

Sinclair, M., Lagan, B.M., Dolk, H. and McCullough, J.E., 2018. An assessment of pregnant women's knowledge and use of the Internet for medication safety information and purchase. Journal of advanced nursing, 74(1), pp.137-147.

Swar, B., Hameed, T. and Reychav, I., 2017. Information overload, psychological ill-being, and behavioral intention to continue online healthcare information search. Computers in Human Behavior, 70, pp.416-425.

Thornton, J., 2018. How can doctors meet relatives' information demands?. BMJ, 363, p.k4514.

Van De Belt, T. H., Engelen, L. J., Berben, S. A., \& Schoonhoven, L. (2010). Definition of Health 2.0 and Medicine 2.0: a systematic review. Journal of Medical Internet Research, 12(2), 1-14.

Walsh, D., and Devane, D. (2012). A Metasynthesis of Midwife-Led Care. Qual Health Res, 22(7), 897-910.

Walsh, T., 2018. "Doing midwifery my way"-Triumphs and challenges of 8 years in a small private practice. Women and Birth, 31, pp.S23-S24.

Wenger-Trayner, E., Fenton-O'Creevy, M., Hutchinson, S., Kubiak, C. and Wenger-Trayner, B. eds., 2014. Learning in landscapes of practice: Boundaries, identity, and knowledgeability in practice-based learning. Routledge. 